\title{
Defining hypotension in the emergency department and in the pre-hospital setting: A hospital-based cohort study
}

\author{
Anders KB Kristensen ${ }^{1 *}$, Jon G Holler ${ }^{1}$, Søren Mikkelsen², Jesper Hallas ${ }^{3}$, Annmarie Lassen ${ }^{1}$ \\ From 6th Danish Emergency Medicine Conference \\ Odense, Denmark. 20-21 November 2014
}

\section{Background}

Systolic blood pressure is a key parameter when identifying patients in shock. However, the systolic blood pressure level below which a given patient should be considered hypotensive is subject to debate. Furthermore, recent studies have advocated higher systolic blood pressure thresholds than the traditionally recognized $90 \mathrm{mmHg}$. The aim of this study was to identify the best performing systolic blood pressure thresholds with regards to predicting 7-day mortality and to evaluate the applicability of these in the emergency department and in the pre-hospital setting.

\section{Methods}

A hospital-based cohort study from Odense University Hospital of all adult patients in the emergency department between 1995 and 2011, all patients transported to the emergency department in non-physician staffed ambulances in the period 2012-2013, and all patients serviced by the physician staffed ambulances in Odense between 2007 and 2013. Exposure was the first recorded systolic blood pressure and the main outcome was 7-day mortality. Best performing thresholds were identified with methods based on receiver operating characteristics and multivariate regression. Performance of systolic blood pressure thresholds was evaluated with standard summary statistics for diagnostic tests.

\section{Results}

7-day mortality rates varied from $1.8 \%$ (95\% CI [1.7, 1.9]) of 112,727 patients in the emergency department to $2.2 \%$ (95\% CI $[2.0,2.5])$ of 15,862 patients in the non-physician staffed ambulance and 5.7\% (95\% CI [5.3, 6.2]) of 12,270 patients in the physician staffed ambulance cohort. Best performing thresholds ranged from 95 to $119 \mathrm{mmHg}$ in the emergency department, 103-120 $\mathrm{mmHg}$ in the non-physician staffed ambulance, and 101-115 mmHg in the physician staffed ambulance.

\section{Conclusions}

A systolic blood pressure threshold of $100-110 \mathrm{mmHg}$ might be a clinically relevant trigger point in the emergency department and the pre-hospital setting.

\section{Authors' details}

${ }^{1}$ Department of Emergency Medicine, OUH Odense University Hospital, Odense, Denmark. ${ }^{2}$ Department of Anaesthesiology and Intensive Care Medicine, OUH Odense University Hospital, Odense, Denmark. ${ }^{3} \mathrm{Clinical}$ Pharmacology, Institute of Public Health, University of Southern Denmark, Odense, Denmark.

Published: 16 July 2015

doi:10.1186/1757-7241-23-S1-A11

Cite this article as: Kristensen et al:: Defining hypotension in the emergency department and in the pre-hospital setting: A hospitalbased cohort study. Scandinavian Journal of Trauma, Resuscitation and Emergency Medicine 2015 23(Suppl 1):A11.

\footnotetext{
* Correspondence: anders.bruun.kristensen@rsyd.dk

'Department of Emergency Medicine, OUH Odense University Hospital,

Odense, Denmark

Full list of author information is available at the end of the article
} 